\title{
Clinical and Endocrine Side-effects of Methylprednisolone Acetate as used in Hay-fever
}

\author{
M. A. GANDERTON, ${ }^{*}$ M.B., B.S.; V. H. T. JAMES, $\dagger$ D.sC.
}

\begin{abstract}
Cummary: Eight patients were treated with two $80-\mathrm{mg}$. $\checkmark$ doses of methylprednisolone acetate (Depo-Medrone), given at an interval of two weeks. Pituitary-adrenal function was assessed before, during, and after treatment.

Plasma cortisol levels were depressed maximally 72 hours after each injection of methylprednisolone acetate, and then gradually returned to normal. The adrenocortical response to administered corticotrophin was similarly affected; in seven patients normal values were again recorded three weeks after the second injection of methylprednisolone acetate. One patient whose adrenal function had returned to normal still showed some degree of pituitary suppression eight weeks after his second injection. Several side-effects were noted, and clinically the patients fared less well than a larger series studied during the previous year.
\end{abstract}

\section{Introduction}

Methylprednisolone acetate (Depo-Medrone), a slow-release steroid for injection, is used in the treatment of allergic and other disorders but no information is available to indicate the effect of this treatment on the hypothalamicpituitary-adrenal axis. It seemed desirable, therefore, to assess hypothalamic-pituitary-adrenal function in a group of patients receiving methylprednisolone acetate in the dosage used for a recent trial of hay-fever treatment (Ganderton, Brostoff, and Frankland, 1969), when two 80-mg. injections of methylprednisolone acetate were given at an interval of two weeks. The effect on the resting plasma cortisol level, on the response of the adrenal gland to synthetic adrenocorticotrophic hormone (Synacthen), and on the plasma cortisol response to the stress of insulin-induced hypoglycaemia was studied.

\section{Scheme and Method of Trial}

During the spring of 1968 the purpose and requirements of our study were explained to patients for whom treatment with intramuscular methylprednisolone appeared suitable, and volunteers were selected from those who worked near St. Mary's Hospital and were willing to attend for repeated investigations. Eight patients were studied: six suffered from seasonal hay-fever and had presented too late for preseasonal hyposensitization, one suffered from intrinsic asthma, and one from urticaria. All except the asthmatic patient were outpatients.

\footnotetext{
* Clinical Assistant, Allergy Department, the Wright-Fleming Institute of Microbiology, St. Mary's Hospital Medical School, London, W.2.

† Professor of Chemical Endocrinology, St. Mary's Hospital Medical School, London, W.2.
}

Methylprednisolone acetate $80 \mathrm{mg}$. was injected intramuscularly on day 1 and day 15 of the trial (except in Case 1, see Fig. $2 \mathrm{~A}$, who inadvertently received her second dose on day 10).

Before each injection, and at regular intervals subsequently, blood was withdrawn for determination of the resting plasma cortisol level, and the response of the adrenal gland to stimulation with synthetic adrenocorticotrophic hormone was measured. For this purpose the rapid test for adrenocortical function described by Wood, Frankland, James, and Landon (1965) was used and the test was repeated at weekly intervals until normal values were obtained-that is, a resting plasma cortisol level above $5 \mu \mathrm{g} . / 100 \mathrm{ml}$., an increment of at least 8 $\mu \mathrm{g} . / 100 \mathrm{ml} .30$ minutes after the injection of corticotrophin, and a stimulated value of $20 \mu \mathrm{g} . / 100 \mathrm{ml}$. or higher. Plasma cortisol levels were estimated by an automated technique as described elsewhere (Townsend and James, 1968). The specificity of this method for the estimation of plasma cortisol has been discussed by James, Townsend, and Fraser (1967).

Though availability of patients determined the time at which blood samples could be taken, all resting samples from any one patient were taken at the same time, the patient thereby acting as his own control.

In six patients hypothalamic-pituitary-adrenal function was assessed by measuring the adrenal response to the stress of hypoglycaemia (Greenwood, Landon, and Stamp, 1966). This was done about one week after the adrenal response to corticotrophin had returned to normal.

\section{Results}

Effects on Resting Plasma Cortisol.-Fig. 1 shows the resting plasma cortisol levels as means of three-day periods for the group of patients studied. There was a sharp fall immediately after the first dose of methylprednisolone, with subsequent recovery towards the mean pretreatment level of 11 $\mu \mathrm{g} . / 100 \mathrm{ml}$. plasma. Before full recovery had occurred, the second dose of methylprednisolone again produced a depression of the plasma cortisol, which was more pronounced than the previous fall. By day 17 the mean level was $2.7 \mu \mathrm{g} . / 100 \mathrm{ml}$. plasma. The resting levels then slowly increased, though by day 30 they had not achieved the pretreatment level. The results for two individual patients (Cases 1 and 2) are shown in detail in Figs. $2 \mathrm{~A}$ and B, while Fig. 3 shows the variations occurring between individual patients.

Response to Corticotrophin.-Adrenocortical responsiveness to corticotrophin was measured at intervals throughout the treatment; the results are shown in Fig. 4. There was a decrease in adrenal response to corticotrophin which was very pronounced immediately after the second dose of methylprednisolone with subsequent recovery towards normal. By day 38-that is, three weeks after the second dose-the mean response had not quite reached normality, as defined by the criteria stated above, a mean stimulated value of $20 \mu \mathrm{g} . / 100 \mathrm{ml}$. not being reached until day 45 . One patient still showed some degree of adrenal depression on day 45 , reaching a maximum 


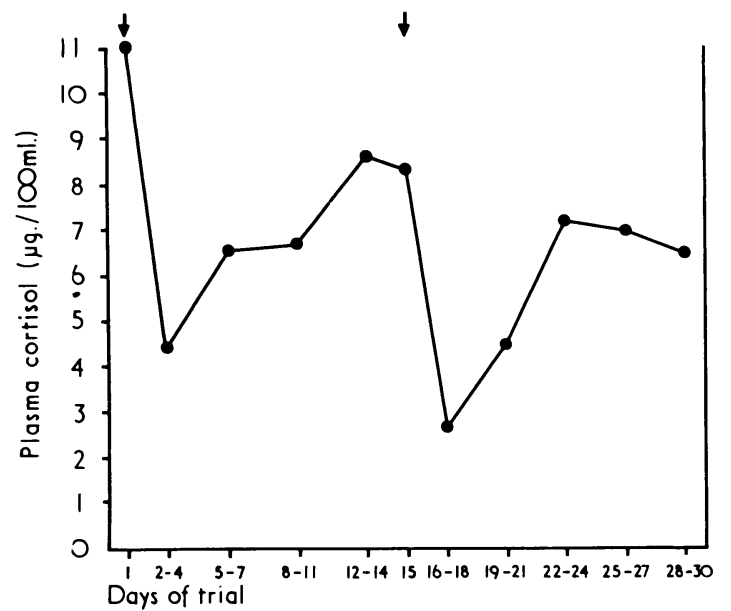

FIG. 1.-Mean resting plasma cortisol values after injection of two $80-\mathrm{mg}$. doses of methylprednisolone acetate (arrows). On days 1 and 15, when injections were given, the mean value for the day was plotted. Other values shown are three-day running means, with one four-day mean for days 11 to 14 .

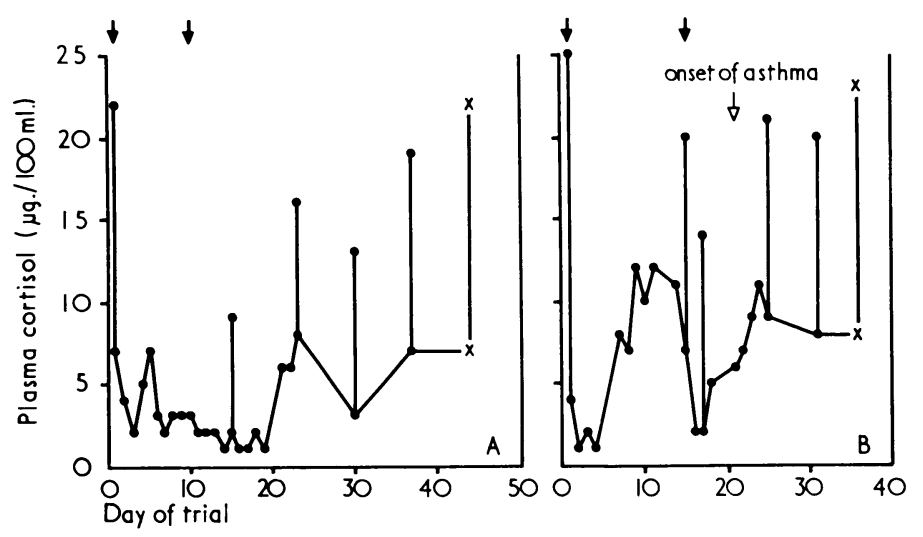

Fig. 2.-A, Case 1, woman aged 48, and B, Case 2, man aged 45. Effect of intramuscular administration of two $80-\mathrm{mg}$. doses of methylprednisolone acetate (arrows) on plasma cortisol levels. The results of the corticotrophin tests $\circ-0$ and the response to hypoglycaemia $x-x$ are shown as resting levels connected to the maximum level achieved during the test. Case 2 developed asthma on the date indicated. Resting samples were taken at 15.30 and 10.00 hours respectively.

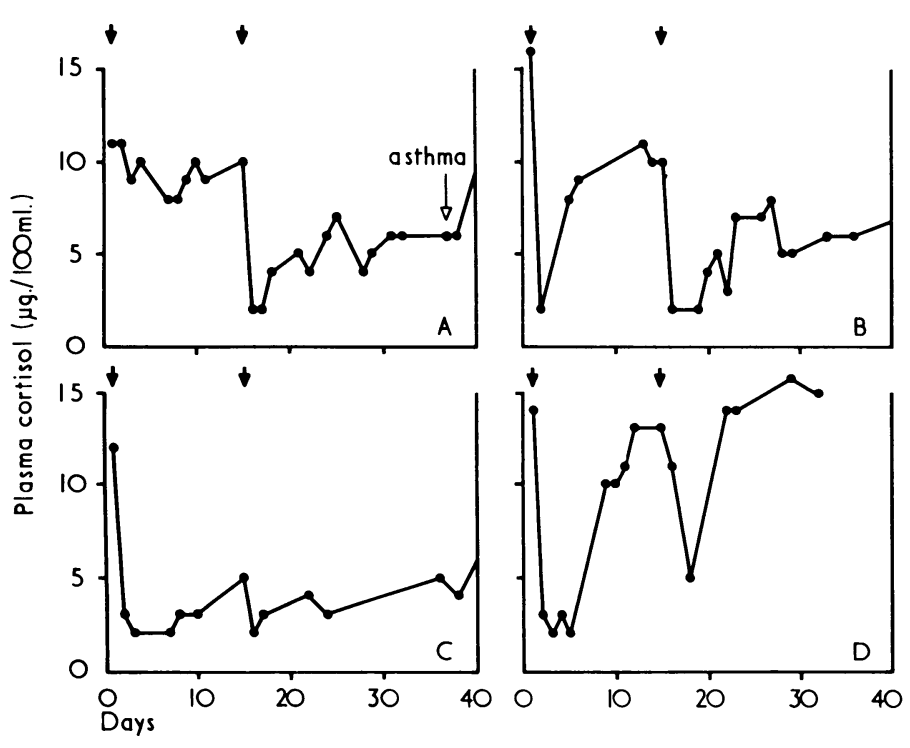

FIG. 3.-Resting plasma cortisoi levels of four patients. Arrows denote injections of methylprednisolone acetate. A, Case 5, woman aged 28; 14.00 hours. Poor clinical result: developed asthma. B, Case 7, man aged 25; 12.30 hours. Good clinical improvement. C, Case 3, man aged $43 ; 16.00$ hours. Good clinical improvement. $D$, Case 8 , man aged aged 43; 16.00 hours. Good clinical improvem

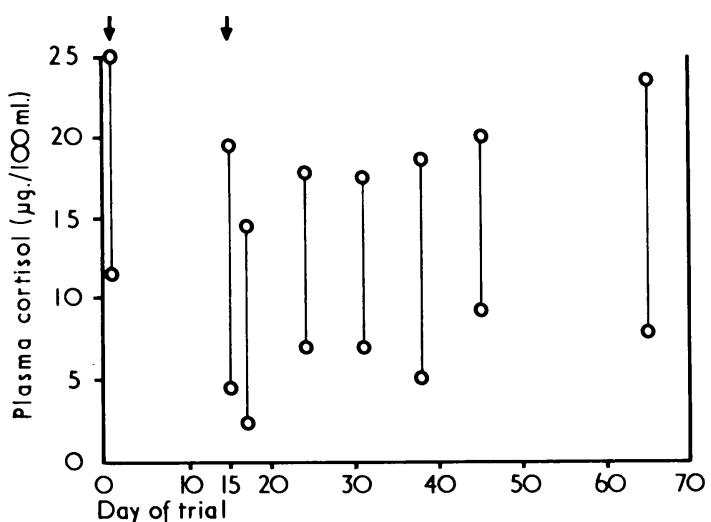

FIG. 4.-Mean plasma cortisol response to administered corticotrophin. Arrows denote injection of $80 \mathrm{mg}$. of methylprednisolone acetate. Mean resting plasma cortisol levels for the day indicated are shown connected to the mean plasma cortisol level reached after stimulation with mean plasma cortisol level reached after stimulation with
corticotrophin.

stimulated level of only $16 \mu \mathrm{g} . / 100 \mathrm{ml}$. Furthermore, although some patients were studied for as long as 60 days after treatment was started, none of them in this period achieved adrenal responses as high as those seen before treatment.

Response to Hypoglycaemia.-The adrenocortical responses of six patients to insulin-induced hypoglycaemia are shown in Fig. 5. These tests were withheld until the results of the patient's corticotrophin test were within normal limits. The insulin tests showed normal responsiveness in all except Case 6 , who still showed some minor degree of suppression of hypothalamic-pituitary-adrenal function as late as 85 days after beginning treatment.

\section{Discussion}

Although the dynamics of steroid absorption after intramuscular and oral administration are undoubtedly different, it appears that the effects on pituitary-adrenal function are broadly similar. Plasma cortisol levels were maximally depressed for 72 hours after the injection of methylprednisolone, presumably while steroid release from the injection site occurred, and then returned towards initial levels. As would be

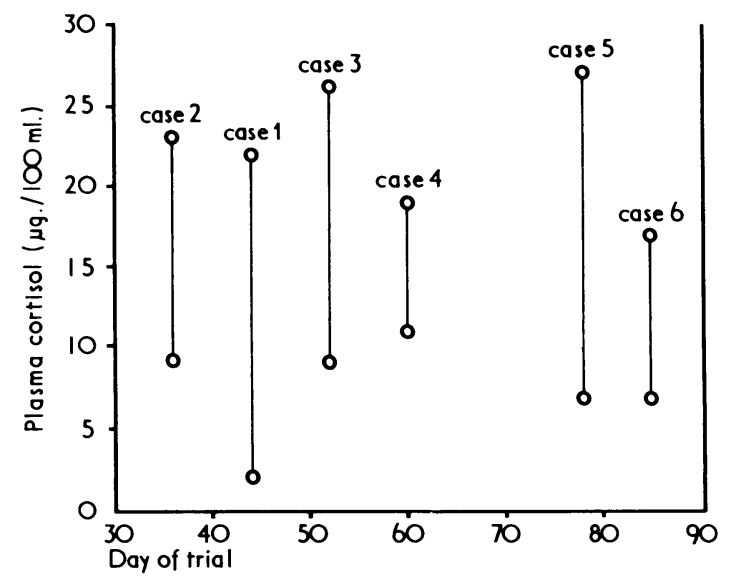

Fig. 5.-Plasma cortisol response to insulin hypoglycaemia. Resting plasma cortisol levels are shown connected to the maximum level reached during hypoglycaemia. Other maximum level reached during hypoglycaemia. Other
details for Cases 1 and 2 are given in Fig. $2 \mathrm{~A}$ and $\mathrm{B}$. 
anticipated, adrenocortical function was depressed and then reverted to within normal limits at varying intervals of time. In only one patient (Case 6) was there any significant depression of the hypothalamic-pituitary-adrenal response to hypoglycaemia when this was investigated at varying times after treatment; there had been no reason to suppose that before treatment this man suffered from any degree of hypothalamic-pituitary-adrenal dysfunction, but, as judged by the response to corticotrophin, adrenal recovery also occurred only very slowly.

It would be reasonable to conclude, therefore, that with the treatment protocol used in this trial-that is, two injections of methylprednisolone acetate at 14-day intervals-the depression of adrenal function constituted little hazard to the patient. If further doses were to be given, suppression could conceivably become more pronounced and would resemble that seen with continuous steroid therapy.

It was noticeable, as with oral steroid therapy, that great variation occurred from one patient to another. Some showed relatively rapid recovery of plasma cortisol levels and others a much slower return to normality; thus Case 1 (Fig. 2 A) showed profound depression of plasma cortisol levels, while levels in Case 2 (Fig. 2 B) rapidly returned to normal. Though only one patient (Case 2) had a pretreatment level of less than $5 \mu \mathrm{g} . / 100 \mathrm{ml}$., the time taken to recover a resting level of 5 $\mu \mathrm{g} . / 100 \mathrm{ml}$. varied from 6 to 30 days after the second injection. It was impossible to predict the type of endocrine response from a patient's physical appearance, age, sex, or initial response to corticotrophin; contrary to widely held belief, the degree of adrenal suppression did not necessarily correlate with clinical improvement. Thus two of our patients continued to have symptoms despite evidence of adrenal suppression, while two reported good clinical improvement though their plasma cortisol levels were only slightly lowered. It should not be assumed that there is no suppression of pituitary-adrenal function because asthma has not been relieved. Unless regular plasma cortisol estimations are performed it is impossible to identify the occasional patient who manifests pronounced adrenal suppression and may therefore be at risk in the case of illness or accident. Such tests are beyond the scope of routine practice.
Clinically our patients fared worse than the larger group studied in the previous trial (Ganderton et al., 1969), where $70 \%$ of patients treated with methylprednisolone acetate were improved, and only $2 \%$ reported that they had developed asthma for the first time. Three of our six hay-fever patients were improved, but three developed asthma for the first time during the summer. As the asthma appeared two to three weeks after the second injection of methylprednisolone acetate, there would be the temptation to administer further doses to this type of patient. As indicated above, such continuing treatment could well produce more pronounced hypothalamic-pituitary-adrenal suppression.

Several conditions which may have been side-effects of steroid treatment were encountered. One patient reported a severe exacerbation of peptic ulcer symptoms; another developed severe cramps which eased when potassium supplements were administered, and this patient also suffered a recurrence of infantile eczema, which had not troubled him since the age of 2 years. A third patient subsequently developed an anterior uveitis of unknown origin, and this may have resulted from reactivation of an old tuberculous lesion.

The incidence of clinical complications and of side-effects which may have been due to steroid treatment was much higher in this small series than one would expect. This may be due to the error in sampling encountered in a small series, but it could also be argued that the information was obtained because patients were interviewed carefully at very frequent intervals.

We wish to thank the nursing staff of the allergy clinic for their help with the numerous tests, and Miss Vivien Smith for performing the plasma cortisol estimations.

\section{REFERENCES}

Ganderton, M. A., Brostoff, J., and Frankland, A. W. (1969). British Medical fournal, 1, 357

Greenwood, F. C., Landon, J., and Stamp, T. C. B. (1966). Fournal of Clinical Investigation, 45, 429.

James, V. H. T., Townsend, J., and Fraser, R. (1967). fournal of Endocrinology, 37, xxviii.

Townsend, J., and James, V. H. T. (1968). Steroids, 11, 497.

Wood, J. B., Frankland, A. W., James, V. H. T., and Landon, J. (1965) 